\title{
Teoria da Estruturação de Giddens e os estudos de práticas avaliativas*
}

\section{| ${ }^{1}$ Gisele O’Dwyer, ${ }^{2}$ Ruben Araujo de Mattos |}

Resumo: O SUS, apesar do seu arcabouço jurídicoinstitucional favorável às práticas de qualidade, não produziu muitas das aspiraçōes pretendidas. As ferramentas tradicionais do planejamento não têm sido suficiente para o projeto de mudanças de práticas no SUS. Esse artigo pretende propor a Teoria da Estruturação como uma ferramenta de avaliação nos serviços. Pode-se dizer que o debate mais atual sobre avaliação está centrado: nos tipos de estudos e modos de incorporar simultaneamente metodologias qualitativas e as tradicionais quantitativas; na utilização, pelos serviços, dos resultados das pesquisas de avaliação; e na institucionalização da avaliação. Outro argumento para uma avaliação mais efetiva é que os conhecimentos dos profissionais e dos usuários têm que ser incorporados no sentido de proporcionar reflexão e produzirem-se mudanças. A Teoria da Estruturação é identificada como uma estratégia metodológica por permitir uma reflexão a partir do conhecimento de uma dada estrutura e de uma interpretação das consequências da ação a partir do acesso ao agente. Essa teoria nos proporciona recursos para análises institucionais mais amplas e simultaneamente é uma ferramenta potente para avaliações situadas em ambientes microssociais. Acessar o agente através do seu discurso e de sua prática e observar "em ato" outras influências dos sistemas sociais que atuem sobre as circunstâncias da ação é uma forma de "elucidar os processos concretos da vida social" e permitir uma maior reflexividade dos atores sobre sua prática.

\footnotetext{
1 Doutora em Saúde Pública pelo IMS/UERJ; pesquisadora do DAPS/ENSP/FIOCRUZ. Endereço eletrônico: odwyer@ensp. fiocruz.br

${ }^{2}$ Doutor em Saúde Pública pelo IMS/UERJ; professor adjunto do Departamento de Planejamento e Administração de Saúde do IMS-UERJ. Endereço eletrônico: ruben@ims.uerj.br
}

> Palavras-chave: teoria da estruturação; práticas avaliativas; avaliação em saúde. 


\section{Introdução}

Este artigo teve como inspiração os debates que os autores têm travado junto a alunos, pesquisadores, professores e profissionais de saúde, sobre a qualidade das práticas de saúde no SUS e as possíveis ferramentas metodológicas para análise das mesmas.

Que conhecimentos, valores e constrangimentos produzem as práticas no SUS? E com base em que recursos? Antes de tudo, um arcabouço jurídicoinstitucional e normas advindas das políticas de saúde. Para o SUS, esse arcabouço, que é extremamente favorável às práticas de qualidade, não produziu muitas das aspiraçôes pretendidas, o que vem sendo discutido pela literatura e em diversos fóruns institucionais. Diante dessas dificuldades, cabe fazer a ressalva de que o subfinanciamento é uma coerção estrutural que opera como dificultador de uma boa prática.

É importante compreender a prática dos serviços como um processo social complexo. $\mathrm{O}$ trabalho em saúde reflete valores da sociedade que influenciam os profissionais e a população atendida, não sendo, portanto, completamente controlável. Fauerwerker (2005) pontua que os atores têm diferentes intencionalidades que disputam o sentido geral do trabalho, assim como os gestores, usuários e propositores de políticas. Para desvendar o processo social que implica práticas diversas, cabe refletir sobre a capacidade de produção, inovação e superação dos profissionais de saúde, destacando a grande autonomia do trabalho médico.

Um desafio posto para a gestão, a gerência e as equipes de trabalho nos serviços no âmbito do SUS é o de (re)criar projetos coletivamente sustentados, em um processo que não pode ser dissociado da (re)criação de novos sujeitos sociais dispostos por defender certas crenças e valores (MATTOS, 1999).

Giddens (1984), ao tratar das práticas sociais, não aceita o dualismo social/ individual, onde, em uma das versôes, a estrutura seria uma força geradora de práticas que engessam a capacidade de mobilização do agente humano e a outra seria um privilégio da intencionalidade e subjetividade nas práticas sociais. $\mathrm{O}$ autor ressalta que é importante ser sensível às habilidades complexas que os atores possuem para coordenar os contextos de seu comportamento cotidiano, já que têm um considerável conhecimento sobre as condições e consequências do que fazem em suas vidas cotidianas. Esse conhecimento não é inteiramente 
suposto nem fortuito para as atividades deles; assim como as consequências do que fazem não derivam inteiramente de ações intencionais - o que significa dizer que não existe uma estrutura que define tudo, muito menos agentes com autonomia plena (GIDDENS, 1984). A partir desse entendimento da ação social, destaca-se a importância de entender o papel do agente e como ele interpreta o ambiente social.

Os atores, a partir do seu conhecimento, monitoram o ambiente social e sua ação, assim como a de outros atores. Essa monitoração, processo de competência do agente humano, possibilita mudança de práticas rotinizadas (GIDDENS, 1984). Segundo Oliveira (2004), para Giddens, a monitoração reflexiva, a racionalização e a motivação sustentariam a ação cotidiana dos atores sociais.

Os estudos de avaliação também pretendem produzir reflexão dos atores para modificar sua prática e, portanto, valorizam o monitoramento reflexivo que advém dos resultados das pesquisas avaliativas. Em função do exposto propomos uma análise (simplificada e aproximativa) da Teoria da Estruturação de Giddens, seus conceitos e propostas metodológicas, dialogando com a produção referente aos limites e potencias das avaliações em saúde.

Pretendemos defender o SUS que é repleto de experiências boas (mesmo que pontuais). Entretanto, não se pode ignorar seu processo de desgaste, também baseado na experiência da população e profissionais. Entendemos que o projeto de mudança é coletivo, exige uma postura ética de solidariedade e é sobre como operar essa reflexão que iremos nos deter. Para tal, visitaremos a produção teórica sobre avaliação em saúde e seus questionamentos mais atuais, propondo como uma possível estratégia metodológica, a Teoria da Estruturação (GIDDENS, 1984).

\section{As práticas avaliativas}

Tradicionalmente, a avaliação da qualidade dos serviços é uma ferramenta da gestão que visa à melhoria da assistência através do planejamento. Os estudos de avaliação, além de serem ferramentas do planejamento e da gestão, são produtores de conhecimento entre outras atribuições.

$\mathrm{Na}$ literatura, os tipos de uso da avaliação podem ser categorizados em três categorias consensuais: a instrumental; a política ou simbólica; e a conceitual. Hartz, Santos e Matilda (2008) concluem que o uso da avaliação não ocorre naturalmente, ele precisa ser facilitado. Sugerem para tal, um quarto tipo de 
uso, o persuasivo, que além da função de mediador, supera a tradicional noção de transferência de conhecimento. Para ir além do termo uso, sugerem o termo influência, que teria três dimensões analíticas: a fonte (processos e resultados); a intencionalidade; e a temporalidade (HARTZ; SANTOS; MATILDA, 2008).

Não pretendemos analisar a área de avaliação sob o ponto de vista da produção teórica (tarefa já realizada por alguns autores), e sim refletir sobre seu potencial de transformação das práticas ou sobre a "intencionalidade" dessa abordagem.

As práticas em serviços de saúde têm sido objeto de discussão e análise desde meados do século passado. Donabedian (1982) propôs ferramentas metodológicas, com destaque para a distinção de indicadores de estrutura, processo e resultado que ganharam notoriedade nos anos 80 e continuam úteis mesmo com o avanço teórico ocorrido na área. $\mathrm{O}$ autor, ao tratar dos limites dessa metodologia, já alertava sobre a parcialidade dos estudos de avaliação, o que apesar de ser um limitante, não desmerece o resultado das pesquisas nem o potencial de utilização das mesmas.

Uma ressalva feita pelo mesmo autor é que a metodologia baseada em indicadores, pouco retrata sobre a habilidade com que o atendimento é prestado, ${ }^{1}$ valorizando a perspectiva do usuário para esse fim. Apesar da forma inovadora, criteriosa e consistente com que Donabedian propôs a avaliação da qualidade da assistência, sua aplicação depende de padrões quantitativos. Os padrões, entendidos como normas obrigatórias ou algo que serve como parâmetro para julgamento, continuam a ser a base da avaliação. Essa utilização prescritiva dos padrões tem sido reavaliada.

Para Hartz, os princípios e diretrizes norteariam a avaliação sem constrangê-la. A literatura internacional traz a noção de padrão aberto, entendendo a necessidade de negociação e adaptação (HARTZ, 2006). Portanto, as metodologias qualitativas são fundamentais enquanto contribuição para avaliação. Se avaliar implica mais do que utilizar padrões (muitas vezes negociados e adaptados) para viabilizar uma práxis social, a pluralidade de instrumentos torna-se necessária. Hartz indica que a pluralidade não é justaposição de instrumentos, mas sua integração em torno de um referente comum (HARTZ, 1999).

Além de instrumento para a gestão, a avaliação de serviços pretende gerar conhecimento. Move-nos neste artigo pensar como esse conhecimento pode ser utilizado, não somente pelos acadêmicos e planejadores, mas principalmente pelos profissionais dos serviços. 
Pinheiro e Silva Junior (2008) identificam como equívoco epistemológico do campo hegemônico da avaliação em saúde, o privilégio exclusivo da expertise acadêmica como a única produtora de conhecimento válido. Esses e outros autores (PINHEIRO; MARTINS, 2009; PINHEIRO; SILVA JUNIOR, 2009) reafirmam a centralidade do usuário para a avaliação das práticas no SUS, sem desconsiderar o olhar e lógica do planejador e do profissional de saúde.

A centralidade no usuário se revelou como uma categoria motriz para o desenvolvimento de novos caminhos analíticos que tivesse como horizonte de estudo a construção de critérios e indicadores de avaliação das ações de saúde mais porosos à participação do cidadão (PINHEIRO; MARTINS, 2009, p. 30).

Sobre o privilégio do conhecimento científico, Teixeira (2006) aponta o risco das práticas avaliativas se transformarem em meros rituais. Esses argumentos indicam a necessária reflexão sobre o quanto os conhecimentos dos profissionais e dos usuários têm que ser incorporados no sentido de refletir sobre as práticas e a partir dessas reflexões, produzirem-se novas práticas, advindas ou não de avaliações.

Santos Filho (2009) defende que usuários, gestores e trabalhadores de saúde devem estar implicados e comprometidos com a produção e avaliação ética na saúde. Para tal propõe como método a avaliaçãolacompanhamento avaliativo, cujos indicadores devam refletir transformações no âmbito da produção dos serviços (mudanças nos processos, organização, resolutividade e qualidade) e da produção de sujeitos (mobilização, crescimento, interação, protagonismo e autonomia dos trabalhadores e usuários).

O "grupo avaliador" foi aprendendo a escapar de uma postura prescritiva e fiscalizatória e foi adquirindo mais segurança/autonomia para olhar avaliativamente sem precisar excluir; aprendendo a envolver o outro como parceiro e não como "devedor de uma meta/dívida"; passando a ter mais habilidade para colocar em análise a própria concepção de metas - sua compreensão e formulação dentro de um objetivo, sua capacidade de refletir intenções, seus condicionantes, parâmetros e fontes de verificação; entender a previsão de um objetivo/meta não numa "dureza" de buscar um resultado a "qualquer custo" ou de guiar a medida/resultado por um valor absoluto, mas sim relativizando-o em relação a variáveis do contexto de trabalho (SANTOS, FILHO, 2009, p. 99).

Ou seja, uma avaliação que utiliza ferramentas quantitativas e qualitativas e que associada à garantia dos direitos sociais (avaliação de justiça) pretende romper o tensionamento entre o usuário e o profissional, que para lidar com as demandas dos usuário, se refugia nas normas e nas falhas do sistema (SANTOS FILHO, 2009). 
Essas reflexões nos trazem elementos para entender que a utilização das ferramentas tradicionais do planejamento não é suficiente para o projeto de mudança no SUS. Não ser suficiente não corresponde a não ser útil, mas nos indica que é necessário parcimônia, menos onipotência (CAMARGO JR., 2003) e entender, como tão bem nos ensina Giddens, que os agentes humanos têm um conhecimento que pode ou não gerar mudanças a partir de um monitoramento reflexivo e que a estrutura é sempre o meio e o resultado da conduta que ela própria organiza (GIDDENS, 1984).

\section{A Teoria da Estruturação}

Uma inquietação ao propor o estudo das práticas é revelar o quanto os atores individualmente são responsáveis pela perpetuação ou mudança das mesmas. Para tal, alguns conceitos são necessários frente a difícil tarefa de "elucidação dos processos concretos da vida social” (GIDDENS, 1984). Propomos que a Teoria da Estruturação (GIDDENS, 1984) apresenta elementos que trazem novas possibilidades para elucidar essas questões.

Um conceito fundamental da Teoria da Estruturação, e que identificamos como primordial para explicar as práticas nos serviços por embasar as ações humanas, é o de rotinização.

A rotina (tudo que é feito habitualmente) constitui um elemento básico da atividade social cotidiana [...]. A natureza repetitiva de atividades empreendidas de maneira idêntica dia após dia é a base material do que eu chamo de "caráter recursivo" da vida social. [...] A rotinização é vital para os mecanismos psicológicos por meio dos quais um senso de confiança ou segurança ontológica é sustentado nas atividades cotidianas da vida social. Contida primordialmente na consciência prática, a rotina introduz uma cunha entre o conteúdo potencialmente explosivo do inconsciente e a monitoração reflexiva da ação que os agentes exigem (GIDDENS, 1984, p. XXV).

Para entender a monitoração reflexiva da ação, o autor defende que o trabalho empírico deve reconhecer aspectos que estão além do que é traduzido discursivamente. Tratam-se dos componentes não discursivos da consciência, a consciência prática, que permite acesso à cognoscitividade dos agentes. A consciência prática seria um aprendizado que acontece naturalmente assim como o aprendizado da linguagem; o que os atores sabem (creem) acerca das condiçóes sociais, incluindo especialmente as de sua própria ação, mas não podem expressar discursivamente; nenhuma barreira repressiva, entretanto, protege a consciência prática, como acontece com o inconsciente (GIDDENS, 1984). 
As capacidades reflexivas do ator humano estão caracteristicamente envolvidas, de um modo contínuo, no fluxo da conduta cotidiana, nos contextos da atividade social. Mas a reflexividade opera apenas parcialmente num nível discursivo. O que os agentes sabem acerca do que fazem e de por que o fazem - sua cognoscitividade como agentes - está largamente contido na consciência prática. Esta consiste em todas as coisas que os atores conhecem tacitamente sobre como "continuar" nos contextos da vida social sem serem capazes de lhes dar uma expressão discursiva direta (GIDDENS, 1984, p. XXV).

A partir do que os atores sabem a cerca das condições sociais, haveria a monitoração reflexiva da ação. $\mathrm{O}$ conceito de monitoração reflexiva traduz o caráter deliberado, ou intencional, do comportamento humano, considerado no interior do fluxo de atividade do agente; a ação não é uma série de atos discretos, envolvendo um agregado de intenções, mas um processo contínuo. Os atores não só controlam e regulam continuamente o fluxo de suas atividades e esperam que outros façam o mesmo por sua própria conta, mas também monitoram rotineiramente aspectos sociais e físicos dos contextos em que se movem. Essa monitoração possibilita mudança de práticas rotinizadas.

A continuidade de práticas presume reflexividade, mas esta, por sua vez, só é possível devido à continuidade de práticas que as tornam intimamente "as mesmas" através do espaço e do tempo. Logo, a "reflexividade" deve ser entendida não meramente como "autoconsciência", mas como o caráter monitorado do fluxo contínuo da vida social (GIDDENS, 1984, p. 3).

A monitoração é um processo de competência do agente humano e que ocorre continuamente no seu cotidiano. Portanto, o agente, a partir do seu conhecimento, subjetividade, intencionalidade e consciência prática, atua e monitora o ambiente social e sua atuação.

Avançando um pouco no entendimento da relação do agente com o social, passamos a descrever como Giddens trata da estrutura e de como ela se relaciona como "meio" e "resultado" (enquanto dualidade) com as "intencionalidades" e "monitoramentos" das ações dos agentes. Na Teoria da Estruturação, considerase "estrutura" o conjunto de regras e recursos implicados de modo recursivo, na reprodução social.

As estruturas são conjuntos de regras que ajudam a constituir e regular as atividades, definido-as como de uma certa espécie e sujeitas a uma determinada gama de sanções. (GIDDENS, 1984, p. 102).

A referência a regras que regulam atividades não deve ser associada diretamente a uma restrição: "A estrutura não deve ser equiparada a restrição, a coerção, mas é 
sempre, simultaneamente, restritiva e facilitadora" (GIDDENS, 1984, p. 30).2

A constituição de agentes e estruturas não são dois conjuntos de fenômenos dados independentemente - um dualismo -, mas representam uma dualidade. A dualidade da estrutura é sempre a base principal das continuidades na reprodução social através do tempo e espaço. A dualidade pressupõe a estrutura como meio e resultado da conduta que ela recursivamente organiza. As propriedades estruturais de sistemas sociais não existem fora da ação, mas estão cronicamente envolvidas em sua produção e reprodução. Portanto, Giddens faz uma reconciliação entre estrutura e ação através da dualidade da estrutura, implicando agentes e recursos.

Assim, a concepção de ação na teoria da estruturação resiste às polaridades do determinismo total e da liberdade total, ao mesmo passo que preserva todas as possibilidades entre esses dois extremos. (COHEN, 1996, p. 411).

Giddens afirma que, em toda relação social, existe uma dialética de controle envolvendo o acesso assimétrico aos meios (recursos) - e a manipulação desses meios - pelos quais os agentes influenciam o comportamento uns dos outros (COHEN, 1996).

Então as práticas sociais podem ser entendidas como procedimentos, métodos ou técnicas hábeis executadas apropriadamente pelos agentes sociais utilizandose regras e recursos. $\mathrm{O}$ aspecto normativo das regras refere-se às práticas do ponto de vista dos direitos e obrigações e dos modos pelos quais as práticas podem ser executadas. $\mathrm{O}$ aspecto semântico das regras refere-se ao significado qualitativo e processual das práticas, associadas com o seu desempenho. Os recursos são as facilidades ou base de poder a que o agente tem acesso e que ele manipula para influenciar a interação com o outro. Os recursos autoritativos são capacidades que geram o comando sobre as pessoas (oportunidades na vida, posicionamento, organização e relação entre as pessoas). Os recursos alocativos são as capacidades sobre os objetos materiais (GIDDENS, 1984).

A "estrutura" pode ser conceituada abstratamente como dois aspectos de regras: elementos normativos e códigos de significação. Os recursos também são de duas espécies: recursos impositivos, que derivam da coordenação da atividade dos agentes humanos, e recursos alocativos, que procedem do controle de produtos materiais ou de aspectos do mundo material (GIDDENS, 1984, p. XXXV).

Essa descrição dos componentes dos recursos da estrutura e dos aspectos das regras explicita porque a estrutura é simultaneamente restritiva e facilitadora. Giddens defende que só em situações muito restritas a coerção da estrutura sobre 
o agente humano seria total, reforçando que a estrutura é sempre o meio e o resultado da conduta que ela própria organiza. ${ }^{3}$

O entrelaçamento de regras e recursos na conduta institucionalizada resulta no que Giddens chama de estratégias de controle: os modos pelos quais os agentes aplicam seu conhecimento a respeito da manipulação dos recursos a que têm acesso para reproduzir a sua autonomia estratégica relativamente às açôes dos outros (COHEN, 1996, p. 433).

A partir dessa revisão dos conceitos da Teoria da Estruturação, passamos a discutir a utilização dessa teoria para os estudos empíricos. Inicialmente essa teoria permite uma reflexão a partir do conhecimento de uma dada estrutura e de uma interpretação das consequências da ação a partir do acesso ao agente. As práticas podem ser entendidas como continuidades de encontros mais restritos (integração social) ou podem estabelecer conexões mais amplas no tempo e no espaço (integração sistêmica).

O que é especialmente útil para a orientação da pesquisa é o estudo, primeiro das interseçõos rotinizadas de práticas que constituem os "pontos de transformação" nas relações estruturais; e, segundo, dos modos como as práticas institucionalizadas estabelecem a conexão entre a integração social e a integração do sistema (GIDDENS, 1984, p. XXXV).

Os agentes devem ter reconhecida a sua cognoscitividade e sua aptidão em dizer acerca das condições de suas ações e de outros agentes. Aptidão que não se restringe ao que eles traduzem discursivamente, já que o agente também monitora um conhecimento tácito sobre o continuar das práticas rotineiras. Daí a importância de indicar que esse conhecimento pode ser acessado através da consciência prática e/ou discursiva.

A vida social pode, com muita frequência, ser previsível em seu curso, mas sua previsibilidade, em muitos de seus aspectos, são os atores que "fazem acontecer". Entretanto, em muitas ocasióes, é no estudo do que é não previsível que as possibilidades de mudança são mais potentes.

$\mathrm{O}$ conceito de consequências impremeditadas é aqui tratado como as consequências não previstas de atos intencionais ou não, com as quais nos deparamos ao estudar as práticas no contexto da vida social.

A vida social, em muitos aspectos, não é um produto intencional de seus atores constituintes, embora a conduta no dia - dia seja cronicamente levada a cabo de modo deliberado. É no estudo das consequências impremeditadas da ação, como enfatizei com frequência, que serão encontradas algumas tarefas mais características das ciências sociais (GIDDENS, 1984, p. 404). 
Daí a importância de conectar consequências impremeditadas da ação com práticas institucionalizadas, aquelas que estão profundamente enraizadas no tempo e no espaço. As consequências impremeditadas, sejam elas positivas ou não, são uma razão para profissionais reverem e modificarem suas práticas. Essa análise considera a imprevisibilidade não desconsiderando a intencionalidade, a racionalidade, valores e subjetividades dos agentes investidos na ação social.

Acessar o agente através do seu discurso e de sua prática e observar "em ato" outras influências dos sistemas sociais que atuem sobre as circunstâncias da ação é uma forma de "elucidar os processos concretos da vida social" e permitir uma maior reflexividade dos atores sobre sua prática.

[...] existem fatores causais influenciando a ação sem atuar através da racionalização. Segue-se do que foi anteriormente dito que esses fatores são de dois tipos: influências inconscientes e influências que afetam as circunstâncias da ação, em cujo âmbito os indivíduos levam a efeito sua conduta. (GIDDENS, 1984, p. 407).

Essas últimas influências são as mais importantes, segundo Giddens, porque existem elementos nos contextos sobre os quais os atores não têm controle. São características facilitadoras ou coercivas do contexto.

Toda ação ocorre em contextos que, para qualquer ator, incluem muitos elementos que este não ajudou a produzir nem possui qualquer controle significativo sobre eles. Essas características facilitadoras e coercivas dos contextos de ação incluem fenômenos materiais e sociais (GIDDENS, 1984, p. 407).

São as "circunstâncias da ação": As formas como esses fenômenos sociais e materiais influenciam enquanto facilitadores e restritores exemplificam o que Giddens chama de dualidade da estrutura. Essas circunstâncias seriam simultaneamente meio e resultado da ação. Um tipo de enquadramento metodológico proposto por Giddens para a pesquisa empírica é a análise institucional ${ }^{4}$ e a análise de conduta estratégica.

$\mathrm{Na}$ análise da conduta estratégica, o foco incide sobre os modos como os atores sociais se apóiam nas propriedades estruturais para a constituição de relações sociais [...]. A análise da conduta estratégica significa dar primazia às consciências discursivas e práticas e às estratégias de controle dentro de limites contextuais definidos. As propriedades institucionais dos cenários de interação são metodologicamente supostas como "dadas" (GIDDENS, 1984, p. 339).

Esse tipo de análise sugere uma concentração nas atividades contextualmente situadas de grupos definidos de atores, dialogando mais com as práticas avaliativas nos serviços. 
Analisar a estruturação de sistemas sociais significa estudar os modos como tais siste-

mas, fundamentados nas atividades cognoscitivas de atores localizados que se apóiam em regras e recursos na diversidade de contextos de ação, são produzidos e reproduzidos em interação (GIDDENS, 1984, p. 30).

A teoria da Estruturação nos proporciona recursos para análises institucionais mais amplas e simultaneamente é uma ferramenta potente para avaliações situadas em ambientes microssociais.

\section{Conclusão}

Acreditamos que a teoria da estruturação de Giddens é uma ferramenta para o estudo das práticas nos serviços de saúde, pelo seu potencial explicativo e analítico e, especialmente, porque esta teoria possibilita abrangência de uso. Ela é compatível com outros métodos e estratégias de pesquisa e não constrange porque não parte de limites pré-estabelecidos e, principalmente, porque aposta na transformação, não baseada exclusivamente nas intenções dos atores ou nos recursos estruturais. Uma transformação que cabe entre os extremos do potencial da estrutura e do potencial do agente e que é permeada pela monitoração reflexiva dos atores sociais. Ou seja, a teoria da estruturação fornece uma ontologia dos potenciais (COHEN, 1996). ${ }^{5}$

Os conceitos da teoria da estruturação, como no caso de qualquer perspectiva teórica
concorrente, devem ser considerados, para muitos fins de pesquisa, nada mais do
que recursos sensibilizadores. Quer dizer, eles podem ser úteis para se refletir sobre
problemas de pesquisa e para a interpretação dos resultados de estudos (GIDDENS,
1984, p. 385).

Pode-se dizer que o debate mais atual sobre avaliação está centrado: nos tipos de estudos e modos de incorporar simultaneamente metodologias qualitativas e as tradicionais quantitativas; na utilização, pelos serviços, dos resultados das pesquisas de avaliação; e na institucionalização da avaliação. Essa visão mais inclusiva da importância dos atores locais para a avaliação parece ser consensual. De modo geral, a evolução classificatória dos tipos de estudos ocorreu no sentido de incluir elementos para além das normas e critérios de julgamento, incluindo a perspectiva de diferentes atores e contextualizando a avaliação.

Deslandes (1997) propõe que a unidade de análise deve ser a atuação em serviço e não o serviço em si. A categoria atuação em serviço contemplaria as relações que fundam a estrutura do serviço, seus processos e ainda incluiria o 
conjunto de representações articuladas pelos atores sociais sobre essa atuação (DESLANDES, 1997). Portanto, essa categoria dialoga facilmente com os conceitos propostos por Giddens.

A utilização das ferramentas tradicionais do planejamento não é suficiente para o amplo projeto de mudanças de práticas no SUS. Não ser suficiente não corresponde a não merecer investimento, mas que devemos ter consciência da multiplicidade de fatores envolvidos para gerar essas práticas e entender, como tão bem nos ensina Giddens, que os agentes humanos podem ou não gerar mudanças, mas que essa mudança se dará a partir de sua reflexão e de estratégias de mobilização de recursos.

Como apontamos, as práticas avaliativas incluem cada vez mais metodologias qualitativas, independente do uso das quantitativas. Portanto, mais do que descrever ferramentas e aderir a teorias, esperamos contribuir com os estudos efetuados em ambientes mais restritos de práticas que podem ou não estabelecer conexões sistêmicas mais amplas.

\section{Referências}

CAMARGO JR., K., R. Biomedicina, saber \& ciência: uma abordagem crítica. São Paulo. Ed HUCITEC, 2003. 195 p.

COHEN I. J. Teoria da estruturação e práxis social. In: GIDDENS, A.; TURNE, J. (Org.). Teoria social hoje. São Paulo: UNESP, 1996, p. 393- 446.

DESLANDES, S. F. Concepções em pesquisa social: articulações com o campo da avaliação em serviços de saúde. Cad. Saúde Públ., Rio de Janeiro, v. 13, n. 1. p. 103-107, jan-mar, 1997. DONABEDIAN, A. Exploration in quality assesment and monitoring. Volume II. The critera anda Standards of quality. Ann Arbor: Health Administration Press, 1982, 505p.

FAUERWERKER, L. M. Modelos tecnoassistenciais, gestão e organização do trabalho em saúde: nada é indiferente no processo de luta para a consolidação do SUS. Interface - comunic, saúde, educ. Botucatu, v. 9, n. 18, p. 489-506, set/dez 2005.

GIDDENS, Anthony. A constituição da sociedade. São Paulo: Martins Fontes, 1984. 458p. HARTZ, Z. M. A. Institutionalizing the evaluation of health programs and policies in France: cuisine internationale over fast food and sur mesure over ready-made. Cadernos de saúde publica, Rio de Janeiro, v. 15, n. 2, p. 229-259, abr./jun. 1999.

HARTZ, Z. M. A. Princípios e padrões em meta-avaliação: diretrizes para os programas de saúde. Ciência e saúde coletiva. Rio de Janeiro, v. 11, n.3, p. 733-738, 2006. 
HARTZ, Z M. A.; SANTOS, E. M.; MATILDA, A. H. Promovendo e analisando o uso e a influência das pesquisas avaliativas. In: HARTZ, Z. M. A.; FELISBERTO, E.; VIERA DA SILVA, L. M. (Org.). Meta-avaliação da atenção básica à saúde: teoria e prática. Rio de Janeiro: Fiocruz, 2008. p. 325-340.

MATTOS, R. A. Em busca de novos projetos coletivos (Debate sobre o artigo de SHRAIBER, L. B.). Ciência e saúde coletiva. Rio de Janeiro, v. 4, n.2, p. 250-252, 1999.

O’DWYER, Gisele. O princípio da integralidade e o SAMU. 2009. 338p. Tese (Doutorado em Saúde Coletiva). - Instituto de Medicina Social, Universidade do Estado do Rio de Janeiro, Rio de Janeiro, 2009.

OLIVEIRA, Lucio Henrique. Cidadãos peregrinos: os "usuários" do SUS e os significados de sua demanda a pronto-socorros e hospitais no contexto de um processo de reorientação do modelo assistencial. Uma análise a partir de usuários do SUS no Município de Juiz de Fora. 2004. 219p. Tese (Doutorado em Saúde Coletiva). - Instituto de Medicina Social, Universidade do Estado do Rio de Janeiro, Rio de Janeiro, 2004.

PINHEIRO, R.; MARTINS, P.H. Apresentação. Avaliação em saúde na perspectiva do usuário: outros olhares possíveis. In: PINHEIRO, R., MARTINS, P.H. (Org.). Avaliação em saúde na perspectiva do usuário: abordagem multicêntrica. Rio de Janeiro: Cepesc, 2009, p. 9-12.

PINHEIRO, R.; SILVA JUNIOR, A.G. Práticas avaliativas e as mediações com a integralidade na saúde: uma proposta para estudos de processos avaliativos na atenção básica. In: PINHEIRO, R.; SILVA JUNIOR, A. G.; MATTOS, R. A. (Org.). Atenção Básica e Integralidade: contribuições para estudos de práticas avaliativas em saúde. Rio de Janeiro: Cepesc, 2008, p. 17-41.

PINHEIRO, R., SILVA JUNIOR, A. G. A centralidade do usuário na avaliação em saúde: outras abordagens. In: PINHEIRO, R., MARTINS, P.H. (Org.). Avaliação em saúde na perspectiva do usuário: abordagem multicêntrica. Rio de Janeiro: Cepesc, 2009, p. 37-52.

SANTOS FILHO, S. B. Avaliação e humanização em saúde: aproximações metodológicas. Ijuí: EdUNIJUI, 2009, 271p.

TEIXIERA, C. F. Institucionalizando a prática de avaliação em saúde: significado e limites (Debate sobre o artigo de FELISBERTO, E). Ciência e saúde coletiva. Rio de Janeiro, v. 11, n.3, p. 572-574, 2006.

\section{Notas}

${ }^{1}$ A metodologia proposta por Donabedian é centrada na atividade do médico e visa a melhor estratégia para o cuidado individualizado.

${ }^{2} \mathrm{Na}$ metodologia de Donabedian, a estrutura é facilitadora (viabiliza, mas sem garantir o processo e resultado do atendimento). A ausência de recursos estruturais é que seria restritiva. 
${ }^{3}$ Nesse sentido, a estrutura para Giddens se aproximaria dos conceitos de processo e resultado de Donabedian.

${ }^{4} \mathrm{~A}$ análise institucional coloca em suspensão as habilidades e a percepção consciente dos atores, tratando as instituições como regras e recursos cronicamente reproduzidos. Haveria, segundo Giddens (1984), uma ressonância da divisão macro/micro.

${ }^{5}$ Sugerimos a tese $O$ principio da integralidade e o SAMU (defendida e orientada pelos autores), para exemplificar o uso dessa teoria para análise de uma prática e política do SUS, o atendimento às urgências no SAMU. 
Giddens' Structuration Theory and studies on evaluation practices

SUS, despite its legal and institutional framework favorable to quality practices, did not produce many of the aspirations desired. The traditional tools of planning have not been sufficient for the design of practice changes in SUS. This paper intends to propose the Theory of Structuration as an assessment tool in services. One could say that the most current debate on evaluation focuses on: the types of studies and ways of incorporating both qualitative methods and traditional quantitative ones; in the use, by services, of research results of evaluation, and institutionalization of evaluation. Another argument for a more effective is that the knowledge of professionals and users has to be incorporated in order to provide reflection and to produce change. The Theory of Structuration is identified as a methodology for allowing a reflection from the knowledge of a given structure and an interpretation of the consequences of action based on the access to the agent. This theory provides us with resources to broader institutional analysis and simultaneously is a powerful tool for evaluations located in micro-environments. To access the agent through his speech and his practice and to observe "in action" other influences of social systems that act on the circumstances of the action is one way to "elucidate the concrete processes of social life" and allow for greater reflexivity of the actors on their practice.

Key words: Structuration Theory; evaluation practices; health assessment. 